\title{
Caracterização dos sistemas de produção de ovinos e caprinos na microrregião de Castanhal, Pará
}

\author{
[Characterization of the production systems used for sheep and goats in the micro region of \\ Castanhal, Pará]
}

\section{"Artigo Científico/Scientific Article"}

\author{
Jocélia Fernandes Helmer, Carlos Alberto Oliveira, Valíria Duarte Cerqueira, Pedro Soares \\ Bezerra, Robert Gustavo Sanchez Prado, Claudina Rita de Souza Pires, Gabriela Riet-Correa*
}

Faculdade de Medicina Veterinária, Universidade Federal do Pará, Castanhal-PA, Brasil.

*Autor para correspondência/Corresponding author: E-mail: griet@ufpa.br

\begin{abstract}
Resumo
O objetivo desse trabalho foi caracterizar os sistemas de produção de ovinos e caprinos na microrregião de Castanhal - Pará. Entre março de 2014 a maio de 2015 foram realizadas visitas a 60 propriedades criadoras de ovinos e caprinos da microrregião de Castanhal - PA, onde aplicou-se um questionário epidemiológico para obtenção de dados relacionados ao manejo produtivo, nutricional, sanitário e reprodutivo do rebanho, infraestrutura e gerenciamento das propriedades. O tipo de criação predominante era extensivo, com pastejo contínuo, com suplementação mineral somente em 46,6\% das propriedades. Em 93,4\% das propriedades o reprodutor era mantido junto com as fêmeas o ano inteiro, enquanto em apenas 3,4\% utilizavam estação de monta e em 3,4\% faziam monta controlada. As doenças relatadas como frequentes foram: parasitoses gastrointestinais (90\%), afecções podais $(80 \%)$, mortalidade de cordeiros $(48,4 \%)$, linfadenite caseosa $(31,7 \%)$, mastites $(25 \%)$ e dermatite alérgica $(20 \%)$. Também foram relatados abortos $(10 \%)$, problemas respiratórios $(6,7 \%)$, alterações nervosas $(8,4 \%)$, ceratoconjuntivite $(13,4 \%)$ e ectima contagioso $(13,4 \%)$. A bovinocultura era a principal atividade desenvolvida pela maioria das propriedades do estudo e a ovinocaprinocultura secundária. Em 88,3\% das propriedades não eram comercializados animais para o abate ou os reprodutores. Os resultados deste trabalho demonstraram que o nível de organização das criações de pequenos ruminantes era precário, sem utilização de técnicas de manejo e não possuíam assistência técnica, apresentando elevados índices de mortalidade, principalmente, pelas parasitoses gastrointestinais e problemas podais.
\end{abstract}

Palavras-chave: ovinocaprinocultura; manejo geral; região Norte.

\begin{abstract}
This work aimed to characterize the production systems of sheep and goats in the microregion of Castanhal Pará. Between March 2014 and May 2015, 60 sheep and goat breeding properties were visited in the microregion of Castanhal - PA. Epidemiological questionnaires were applied to obtain data related to the productive, nutritional, health, and reproductive management of the herd, infrastructure, and management of rural properties. Extensive rearing, with continuous grazing, was the most registered type of management and with mineral supplementation only in $46.6 \%$ of the interviewed properties. In $93.4 \%$ of the farms, the breeder was kept together with the females the whole year, while in only $3.4 \%$, they used breeding seasons, and in $3.4 \%$, they did controlled breeding. The diseases reported as the most frequent were: gastrointestinal parasites $(90 \%)$, foot disorders $(80 \%)$, lamb mortality $(48.4 \%)$, caseous lymphadenitis $(31.7 \%)$, mastitis $(25 \%)$, and allergic dermatitis $(20 \%)$. Abortions (10\%), respiratory problems $(6.7 \%)$, nervous disorders (8.4\%), keratoconjunctivitis (13.4\%), and contagious ecthyma were also reported (13.4\%). Cattle breeding was the most registered activity among the studied properties and sheep breeding was a secondary activity. In $88.3 \%$ of the properties, the animals selected for slaughter or breeding were not commercialized. The results of this work demonstrated that the level of organization of small ruminant rearing in the studied
\end{abstract}


region was precarious. There were no management techniques and no technical assistance, with high mortality rates, mainly due to gastrointestinal parasites and feet problems.

Keywords: sheep and goat farming; production, management; North region.

\section{Introdução}

O Brasil possui um rebanho de aproximadamente 17.700 .000 ovinos e 8.900 .000 caprinos, distribuídos nas diferentes regiões do país, sendo que a região Nordeste brasileira possui o maior rebanho, seguida da região Sul (IBGE, 2015). Na região Norte, entre os anos de 1995 e 2009, o número de animais no estado cresceu, passando de 91.541 para 197.739 ovinos e de 34.050 para 91.230 caprinos (IBGE, 2010). Apesar do aumento significativo do rebanho nesse período, entre os anos de 2009 e 2014, o quantitativo do rebanho se manteve estável. No entanto, considerando somente o rebanho da mesorregião de Belém, onde está inserida a microrregião de Castanhal, o rebanho de ovinos e caprinos diminuiu aproximadamente 50\% (IBGE, 2015). Essa redução no quantitativo do rebanho se deve, provavelmente, à falta de programas de assistência técnica para atender o setor, ausência de tecnologias adaptadas à região, falta de mão de obra qualificada e pouco conhecimento dos métodos viáveis de manejo produtivo, reprodutivo, nutricional e sanitário, assim como ocorre em outros estados na região Norte, onde a ovinocaprinocultura é caracterizada por ser uma atividade extensiva, com baixo uso de tecnologia, sem assistência técnica e com baixos índices zootécnicos (Oliveira et al., 2017; Sório et al., 2017). Além disso, as condições climáticas peculiares da região, caracterizada por clima equatorial úmido e altos índices pluviométricos, são favoráveis ao surgimento de alguns problemas sanitários, como as doenças parasitárias, com destaque para a hemoncose, e as doenças podais, como as pododermatites. Portanto, o objetivo desse trabalho foi caracterizar os sistemas de produção de ovinos e caprinos na microrregião de Castanhal, Pará, com a finalidade de identificar os principais entraves para o desenvolvimento da ovinocaprinocultura nessa região.

\section{Material e Métodos}

$\mathrm{O}$ estudo foi realizado na microrregião de Castanhal, Pará, composta pelos municípios de Castanhal, Santa Isabel do Pará, Santo Antônio do Tauá, Inhangapi e Bujaru. No período de março de 2014 a maio de 2015 foram realizadas visitas técnicas a 60 propriedades rurais, sendo 49 pertencentes ao município de Castanhal, quatro (4) ao município de Inhangapi, três (3) a Santa Isabel do Pará, três (3) a Santo Antônio do Tauá e uma (1) a Bujaru. Em 2014 a microrregião de Castanhal contava com 68 propriedades cadastradas na Agência de Defesa Agropecuária do Estado do Pará (ADEPARÁ) como criadoras de ovinos e/ou caprinos. No entanto, em oito dessas propriedades, no momento das visitas, não havia mais animais, e, por isso, não foram incluídas neste estudo. Durante as visitas aplicouse um questionário semiestruturado para obtenção de dados relacionados ao manejo produtivo, nutricional, sanitário e reprodutivo dos rebanhos, assim como dados referentes à infraestrutura e gerenciamento das propriedades. A partir das informações dos questionários foi gerado um banco de dados no Microsoft Excell (2010) onde foi desenvolvida análise descritiva dos dados.

\section{Resultados}

Em $73,4 \%$ das propriedades eram criados somente ovinos, em 8,3\% somente caprinos e em $18,3 \%$ as duas espécies eram criadas concomitantemente. O tamanho dos rebanhos variou de até 20 a 150 animais (Figura 1) e o tamanho das propriedades de até 50 a acima de 300 hectares (ha) (Figura 2).

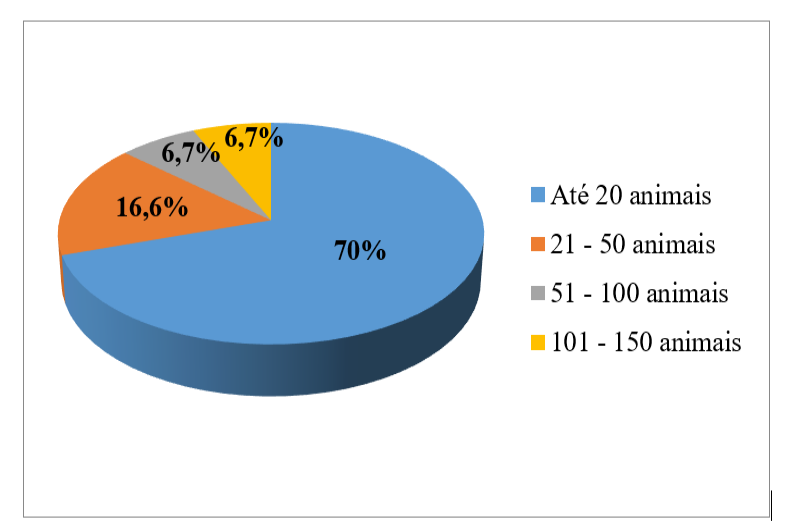

Figura 1. Efetivo de ovinos e caprinos observado em propriedades na microrregião de Castanhal, Pará, no período de março de 2014 a maio de 2015.

Em todas as propriedades as criações de ovinos e caprinos não eram a principal fonte de renda da propriedade. Em apenas $8,3 \%$ das propriedades a ovinocaprinocultura era a principal 
atividade pecuária desenvolvida. Nas demais $(91,7 \%)$ a bovinocultura era a principal atividade de exploração pecuária. Em $88,3 \%$ das propriedades não eram comercializados animais vivos ou abatidos, e a produção se destinava apenas ao consumo na propriedade. Em $73,4 \%$ das propriedades o proprietário não residia na fazenda, ficando responsável pelos animais apenas um funcionário, sendo que este era responsável por outras atividades além da criação de ovinos e/ou caprinos. Nenhuma propriedade possuía assistência técnica especializada.



Figura 2. Tamanho da área territorial de propriedades criadoras de ovinos e caprinos na microrregião de Castanhal, Pará, no período de março de 2014 a maio de 2015 .

A Tabela 1 mostra a infraestrutura disponível nas propriedades para a ovinocaprinocultura. Os dados referentes ao manejo produtivo, reprodutivo e sanitário estão demonstrados nas Tabelas 2, 3 e 4, respectivamente. A Tabela 5 mostra a ocorrência de doenças relatadas pelos produtores.

Tabela 1. Infraestrutura disponível para a ovinocaprinocultura em propriedades criadoras de ovinos e caprinos na microrregião de Castanhal, Pará, no período de março de 2014 a maio de 2015.

\begin{tabular}{|c|c|c|c|}
\hline Instalação & & $\mathbf{N}$ & Frequência (\%) \\
\hline Aprisco coberto & & 44 & 73,4 \\
\hline $\begin{array}{l}\text { Curral adaptado } \\
\text { bovinos }\end{array}$ & de & 07 & 11,7 \\
\hline Abrigo & & 09 & 15,0 \\
\hline Cocho & & 17 & 28,4 \\
\hline Brete/tronco & & 01 & 1,7 \\
\hline Balança & & 03 & 5,0 \\
\hline Baias individuais & & 08 & 13,4 \\
\hline Esterqueira & & 03 & 5,0 \\
\hline Pedilúvio & & 06 & 10,0 \\
\hline
\end{tabular}

Tabela 2. Práticas de manejo produtivo utilizadas em propriedades criadoras de ovinos e caprinos na microrregião de Castanhal, Pará, no período de março de 2014 a maio de 2015.

\begin{tabular}{lcc}
\hline Manejo Produtivo & N & Frequência (\%) \\
\hline Registro de Nascimento & 08 & 13,4 \\
Registro de Mortalidade & 05 & 8,4 \\
Separação zootécnica & 06 & 10,0 \\
Castração de machos & 09 & 15,0 \\
Separação de fêmeas & 03 & 5,0 \\
Identificação dos animais & 05 & 8,4 \\
\hline
\end{tabular}

Tabela 3. Práticas de manejo reprodutivo utilizadas em propriedades criadoras de caprinos e ovinos da Microrregião de Castanhal, PA, no período de março de 2014 a maio de 2015.

\begin{tabular}{lcc}
\hline Manejo Reprodutivo & N & Frequência (\%) \\
\hline Reprodutor mantido & 56 & 93,4 \\
junto com a fêmea & & 3,4 \\
Monta controlada & 02 & 3,4 \\
Estação de monta & 02 & 11,7 \\
Registro & 07 & 38,4 \\
Acasalamento & 23 & \\
\hline
\end{tabular}

Tabela 4. Práticas de manejo sanitário utilizadas em propriedades criadoras de caprinos e ovinos da Microrregião de Castanhal, PA, no período de março de 2014 a maio de 2015.

\begin{tabular}{lcc}
\hline Manejo Sanitário & N & Frequência (\%) \\
\hline Vermifugação & 58 & 96,7 \\
Vermifugação mensal & 25 & 41,7 \\
Vermifugação 4x/ano & 35 & 58,4 \\
Uso de bases & 24 & 40,0 \\
farmacológicas diferentes & & 11,2 \\
Casqueamento periódico & 07 & 8,4 \\
Pedilúvio & 05 & \\
\hline
\end{tabular}

Tabela 5. Principais problemas sanitários relatados por produtores em criações de ovinos e caprinos na microrregião de Castanhal, Pará, no período de março de 2014 a maio de 2015.

\begin{tabular}{lcc}
\hline Doenças & N & Frequência (\%) \\
\hline Verminoses/diarreia & 54 & 90,0 \\
Abortos & 06 & 10,0 \\
Mortalidade de cordeiros e & 29 & 48,4 \\
cabritos & 05 & 8,4 \\
Ectoparasitos & & 6,7 \\
Problemas respiratórios & 04 & 13,4 \\
(pneumonia) & 08 & 25,0 \\
Ceratoconjuntivite & 15 & 80,0 \\
Mastite & 48 & 20,0 \\
Problemas podais & 12 & 13,4 \\
Dermatite alérgica & 08 & 8,4 \\
Ectima contagioso & 05 & 31,7 \\
Alterações nervosas & 19 & \\
Linfadenite caseosa & & \\
\hline
\end{tabular}


Todas as propriedades utilizavam o sistema de criação extensivo, sendo que os animais eram recolhidos aos apriscos ou abrigos no final do dia. O sistema de pastejo predominante era o contínuo $(90 \%)$, seguido pelo rotacionado (10\%). As pastagens mais utilizadas eram o Panicum maximum cv. Massai (40\%) e cv. Mombaça (15\%), seguida por Bachiaria brizantha (10\%) e B. humidicola (5\%). Em $30 \%$ das propriedades o tratador não soube informar o tipo de pastagem utilizada. A suplementação mineral era realizada em $46,6 \%$ das propriedades e apenas 5\% ofertavam concentrado aos animais. Quinze por cento das propriedades faziam adubação das pastagens. A maior parte das propriedades visitadas não possuía controle da sua criação através de ações de gerenciamento, como a pesagem dos cordeiros e cabritos ao nascer, pesagem dos animais para abate e gastos com alimentação e medicações.

\section{Discussão}

Durante as entrevistas foi possível perceber que os produtores desconhecem as técnicas adequadas de manejo sanitário, nutricional, produtivo e reprodutivo.

$\mathrm{O}$ tipo de criação era predominantemente extensivo, com sistema de pastejo contínuo. $\mathrm{Na}$ maioria das propriedades as pastagens eram as mesmas utilizadas para bovinos, sendo que os ovinos e/ou caprinos tinham acesso a toda a área de pastagem da propriedade, já que as cercas não eram específicas para essas espécies. Em um estudo realizado no Rio Grande do Sul, o sistema de criação extensivo também foi predominante, sendo adotado por $70 \%$ das propriedades avaliadas, enquanto $29 \%$ utilizavam sistema semiintensivo e apenas $1 \%$ o intensivo (Silva et al., 2013a). Resultados semelhantes aos observados no Piauí (Silva et al., 2011) e no Ceará (Pinheiro et al., 2000), onde o sistema extensivo era praticado em $71 \%$ e $77,9 \%$ das propriedades avaliadas, respectivamente. Em Pernambuco também predominou o sistema de criação extensivo (Almeida et al., 2006). Já no Cariri (Silva et al., 2013b) e na região semiárida da Paraíba (Riet-Correa et al., 2013), o sistema de criação predominante foi o semi-extensivo.

A suplementação mineral era, na maioria das propriedades, a única prática nutricional adotada $(46,6 \%)$, embora possa ser considerada pouco frequente quando comparada a sua utilização nas regiões Nordeste (Santos et al.,
2011). A suplementação com ração e utilização de capineiras ou silagem também era uma prática pouco habitual. Isso pode ocorrer devido às condições climáticas da região, já que mesmo no período seco as chuvas são frequentes, o que não interfere na disponibilidade de forragem, ao contrário do que ocorre em outras regiões do Brasil, onde a suplementação com ração e o armazenamento de forragem são práticas necessárias durante períodos de estiagem (Bandeira et al., 2007; Santos et al., 2011; RietCorrea et al., 2013; Silva et al., 2013b).

Quanto ao manejo reprodutivo, a estrutura de rebanho é pouco organizada, sem adoção de biotécnicas reprodutivas, como a inseminação artificial (IA). Esta técnica permite agregar valor ao rebanho, por usar reprodutores de elevado padrão genético, utilizar fêmeas fora da estação reprodutiva e padronizar os lotes dos produtos gerados (Alvares et al., 2015). Apesar de somente $38,3 \%$ das propriedades identificarem que ocorre o acasalamento entre animais com grau de parentesco, é possível que esse número seja maior, uma vez que na maioria das propriedades não era realizada a seleção de matrizes e reprodutores no rebanho e nem a castração dos machos excedentes. A baixa utilização de técnicas de manejo reprodutivo, que visam aumentar a produtividade e qualidade do rebanho, também é relatada na região semiárida da Paraíba (Costa et al., 2008) e no Rio Grande do Sul (Silva et al., 2013a). Já na região do Cariri paraibano 33\% dos produtores adotavam estação de monta e 8,3\% utilizavam rufiões (Bandeira et al., 2007), resultados superiores aos observados no presente estudo. A separação dos animais de um rebanho em lotes de acordo com a categoria zootécnica facilita o manejo e evita coberturas indesejáveis (Aquino et al., 2016). A falta de manejo reprodutivo adequado também contribui para a baixa produtividade dos rebanhos na microrregião de Castanhal. O manejo reprodutivo mal conduzido pode levar a altas taxas de mortalidade, perdas zootécnicas e grandes prejuízos econômicos ao produtor (Nogueira et al., 2011).

O baixo registro dos acontecimentos relacionados ao rebanho, como identificação dos animais, registro de pai e mãe, anotação de nascimentos e mortalidade é também um dos fatores que contribuem para um baixo desempenho dos rebanhos estudados, uma vez que a escrituração zootécnica constitui uma das práticas mais importantes para se obter uma boa 
administração das propriedades, viabilizando assim um manejo adequado, controle e seleção eficiente dos animais (Sandoval et al., 2015). Esses resultados são semelhantes aos observados em estudos realizados na região semiárida da Paraíba (Costa et al., 2008; Alencar et al., 2010; Santos et al., 2011; Riet-Correa et al., 2013) e no Rio Grande do Sul (Silva et al., 2013a), onde as criações de pequenos ruminantes assumem uma importância econômica significativa.

O investimento na atividade é mínimo, sendo que na maioria das propriedades a única instalação específica para pequenos ruminantes era o aprisco que, na maioria das vezes, era inadequado, com bebedouros e comedouros improvisados. Na maioria das propriedades a ovinocaprinocultura era uma atividade secundária, sendo a bovinocultura a principal atividade desenvolvida. Além disso, também não era uma atividade comercial, como ocorre nas regiões Sul e Nordeste, já que $88 \%$ das propriedades não comercializavam animais para abate ou reprodutores. Assim como no Rio Grande do Sul (Silva et al., 2013a), a falta de investimento nas criações de ovinos, por ser uma atividade secundária, foi identificada na maioria das propriedades deste estudo.

Na região em estudo, a ovinocaprinocultura é uma atividade pouco expressiva, visto que das 614 propriedades cadastradas no Sistema de Integração Agropecuária do Pará em 2014, apenas 68 constavam como criadoras de ovinos e/ou caprinos. Além disso, no momento da visita oito delas já não tinham mais animais. Muitos produtores relataram que investiram na criação com a intenção de obter lucros através da comercialização de animais, mas devido aos sérios problemas sanitários, não tiveram sucesso e praticamente desistiram da criação. Essa situação ficou bem caracterizada no quantitativo dos rebanhos, visto que quase $70 \%$ das propriedades possuíam até 20 animais. Em 2014, segundo dados da ADEPARA, na microrregião de Castanhal havia 68 propriedades cadastradas como criadoras de ovinos e caprinos, que somavam um total 3.091 ovinos e 556 caprinos. No entanto, no momento das visitas, o total do rebanho das 60 propriedades que ainda criavam esses animais era de 1558 ovinos e 184 caprinos, uma diminuição significativa. Segundo tratadores e proprietários o número de animais foi diminuindo gradativamente devido às altas taxas de mortalidade de animais jovens e adultos.
A ocorrência de parasitoses gastrointestinais foi relatada em $90 \%$ das propriedades. Segundo os produtores e/ou tratadores a mortalidade devido à parasitose é elevada, sendo a palidez da mucosa ocular (anemia) e a papeira (edema submandibular) os principais sinais clínicos relatados, sugestivos de hemoncose (Endo et al., 2014). As parasitoses gastrointestinais, em especial a hemoncose, são, provavelmente, um dos principais limitantes da produção de caprinos e ovinos na região em estudo. Fatores climáticos como temperaturas elevadas e altos índices pluviométricos suportam consistentemente o desenvolvimento larval de $H$. contortus (Hannah et al., 2016). Os resultados dos estudos epidemiológicos das infecções por helmintos gastrintestinais realizados nas demais regiões do Brasil não parecem aplicáveis a essa região, visto que as populações de helmintos gastrintestinais, durante a fase de vida livre, sofrem influências de vários fatores ambientais, os quais podem interferir diretamente no desenvolvimento e sobrevivência das larvas infectantes nas pastagens (Amarante et al., 2004; Molento et al., 2011). As vermifugações frequentes, utilizando de forma indiscriminada diversas bases anti-helmínticas, sem realização de OPG e testes de resistência, como observado no presente estudo, favorece a ocorrência de nematódeos gastrintestinais devido ao desenvolvimento da resistência as principais classes de anti-helmíntico utilizadas (Borges et al., 2015). São necessários, portanto, estudos epidemiológicos que permitam estabelecer medidas de controle adequadas à nossa região.

As afecções podais foram relatadas como um problema grave na maioria das propriedades $(80 \%)$. Problemas podais são as principais causas de claudicação em pequenos ruminantes (Pugh, 2004; Ribeiro, 2007), sendo responsáveis por grandes perdas econômicas, devido à redução no consumo de forragens, no ganho de peso e na produção de leite, além de infertilidade ou descarte prematuro dos animais (Tadich e Hernandez, 2000). A pododermatite infecciosa está entre as enfermidades podais mais frequentes dos ovinos (Kaler e Green, 2008). Embora as afecções podais sejam bem conhecidas pela grande maioria dos produtores da região, pouco se sabe sobre aspectos importantes da doença como etiologia, variações ambientais que causam os surtos, resistência/susceptibilidade das raças de ovinos e caprinos criados na região e medidas 
corretas de controle e profilaxia. O clima equatorial úmido, com altos índices pluviométricos, que favorecem a ocorrência de doenças podais, em especial a pododermatite, faz com que esta enfermidade seja um entrave para o desenvolvimento da ovinocaprinocultura na região. Além disso, a falta de utilização de métodos de manejo simples, mas eficazes, como o casqueamento periódico e a utilização de pedilúvio, como observado no presente estudo, contribuem para a alta frequência de problemas podais (Quinn et al., 2005).

A mortalidade perinatal é outro fator limitante na produção de ovinos e caprinos. Considera-se mortalidade perinatal de ovinos as mortes que ocorrem entre os 60 dias de gestação e os 28 dias após o parto. Essas mortes podem ocorrer antes do parto (abortos), durante o parto ou após o parto. No Rio Grande do Sul, estima-se que morram $15 \%$ a $40 \%$ dos cordeiros nascidos, sendo a principal causa de mortalidade o complexo inanição/ hipotermia, responsável por $56 \%$ a $78 \%$ das mortes (Riet-Correa, 2007). Em um trabalho realizado na região semiárida da Paraíba, as principais causas de morte de cordeiros no período perinatal foram as infecções neonatais $(41,1 \%$ das mortes), seguidas das malformações (23,3\%), distocias (10\%), complexo inanição/hipotermia (10\%), aborto $(4,4 \%)$ e predação $(2,2 \%)$ (Nóbrega et al., 2005). No presente estudo, a mortalidade de cordeiros/cabritos foi relatada em 48,33\% das propriedades e os abortos em $10 \%$. Na região Norte não há dados sobre a ocorrência e frequência das causas de mortalidade perinatal em pequenos ruminantes. Portanto, são necessários estudos que determinem as causas dessas perdas, para que possam ser tomadas as medidas de controle que possibilitem uma melhoria significativa nos índices de produtividade do rebanho caprino e ovino na região. Outras doenças relatadas no presente estudo foram a linfadenite caseosa, em $31,66 \%$ (19) das propriedades e as mastites em $25 \%$ (15), porém com uma ocorrência menor que a observada em outras regiões (Almeida et al., 2006; Bandeira et al., 2007; Alencar et al., 2010; Santos et al., 2011). A dermatite alérgica e o ectima contagioso, relatadas em $12(20 \%)$ e $8(13,33 \%)$ da propriedade, respectivamente, também contribuem para baixa eficiência produtiva dos rebanhos. Embora todas essas enfermidades sejam bem conhecidas em outras regiões, essas afecções se tornam importantes, uma vez que os produtores da região desconhecem as formas de tratamento, controle e profilaxia adequados.

\section{Conclusão}

$\mathrm{Na}$ microrregião de Castanhal, Pará, a ovinocaprinocultura possui baixos níveis produtivos, devido, principalmente, a graves problemas de saúde animal e à ausência de tecnologias adequadas. Esses fatores evidenciam a necessidade de criar alternativas produtivas para a ovinocultura da região que permitam a melhoria dos padrões sanitários, zootécnicos e nutricionais dos rebanhos, tornando a atividade mais rentável e produtiva.

\section{Conflito de interesse}

Os autores declaram não existir conflitos de interesse.

\section{Referências}

Alencar, S.P.; Mota, R.A.; Coelho, M.C.O.C.; Nascimento, S.A.; Abreu, S.R.O.; Castro, R.S. Perfil sanitário dos rebanhos caprinos e ovinos no sertão de Pernambuco. Ciência Animal Brasileira, 11(1): 131-140, 2010.

Almeida, A.C.S.; Ferreira, R.L.C.; Santos, M.V.F.; Silva, J.A.A.; Lira, M.A. Caracterização de produtores e propriedades rurais em três municípios do estado de Pernambuco. Caatinga (Mossoró, Brasil), 19(4): 323-332, 2006.

Alvares, C.T.G.; Cruz, J.F.; Maringá, M.L.F. Técnicas de inseminação artificial e implicações fisiopatológicas em ovinos. PubVet, 9(5): 220-231, 2015.

Amarante, A.F.T.; Bricarello, P.A.; Rocha, R.A.; Gennari, S.M. Resistance of Santa Ines, Suffolk and Ile de France lambs to naturally acquired gastrointestinal nematode infections. Veterinary Parasitology, 120: 91-106, 2004.

Aquino, R.S.; Lemos, C.G.; Alencar, C.A.; Silva, E.G.; Lima, R.S.; Gomes, J.A.F.; Silva, A.F. A realidade da caprinocultura e ovinocultura no semiárido brasileiro: um retrato do sertão do Araripe, Pernambuco. PubVet, 10(4): 271-281, 2016.

Bandeira, D.A.; Castro, R.S.; Azevedo, E.O.; Melo, L.S.S.; Melo, C.B. Características de produção da caprinocultura leiteira na região do Cariri na Paraíba. Ciência Veterinária nos Trópicos, 10(1): 29-35, 2007. 
Borges, S.; Oliveira, A.; Mendonça, L.L.; Viana, J.; Nishi, S.; Julião, F.; Almeida, M. Resistência anti-helmíntica em rebanhos caprinos nos biomas Caatinga e Mata Atlântica. Pesquisa Veterinária Brasileira, 35(7): 643-648, 2015.

Costa, R.G.; Almeida, C.C.; Pimenta, E.C.F.; Holanda, E.V.; Santos, N.M. Caracterização do sistema de produção caprino e ovino na região semiárida do estado da Paraíba. Brasil. Arquivos de Zootecnia, 57(218): 195-205, 2008.

Endo, V.T.; Oliveira, T.C.; Cabral, A.P.M.; Sakamoto, C.A.M.; Ferraro, G.C.; Pereira, V. Prevalência dos helmintos Haemonchus contortus e Oesophagostomum columbianum em pequenos ruminantes atendidos no setor de anatomia patológica - UEM. Revista de Ciência Veterinária e Saúde Pública, 1(2): 112-118, 2014.

Hannah, R.; Cyril, C.; Bolajoko, M.; Phelan, P.; Van Dijk, J.; Baylis, M.; Williams, D.; Morgan, E. Climate-driven changes to the spatio-temporal distribution of the parasitic nematode, Haemonchus contortus, in sheep in Europe. Global Change Biology, 22: 1271-1285, 2016.

Instituto Brasileiro de Geografia e Estatística IBGE, 2010. Disponível em: $\langle\mathrm{httm}$ ://www.sidra.ibge.gov.br $>$. Acesso em: 15 set. 2016.

Instituto Brasileiro de Geografia e Estatística IBGE, 2015. Disponível em: $<\mathrm{httm}$ ://www.sidra.ibge.gov.br>. Acesso em: 15 set. 2016.

Kaler, J., Green, L.E. Naming and recognition of six foot lesions of sheep using written and pictorial information: A study of 809 English sheep farmers. Preventive Veterinary Medicine, 83(1): 52-64, 2008.

Molento, M.B.; Fortes, F.S.; Pondelek, D.A.S.; Borges, F.A.; Chagas, A.C.S.; Torres-Acosta, J.F.; Geldhof, P. Challenges of nematode control in ruminants: Focus on Latin America. Veterinary Parasitology, 180: 126-132, 2011.

Nóbrega, J.E.; Riet-Correa, F.; Nóbrega, R.S.; Medeiros, J.M.; Vasconcelos, J.S.; Simões, S.V.D.; Tabosa, I.M. Mortalidade perinatal de cordeiros no semi-árido da Paraíba. Pesquisa Veterinária Brasileira, 25(3): 171-178, 2005.
Nogueira, D.M.; Eloy, A.M.; Sá, C.O.; Lopes, E.S.; Figueiredo, H.O.; Sá, J.L.; Sousa, P.H. Produção de ovinos e caprinos no Semiárido. Petrolina: Embrapa Semiárido, 2011. 553p.

Oliveira, R.P.M.; Oliveira, F.F.; Passos, A.; Lamarão, C.V. Ovinos de corte no estado do Amazonas: Ênfase em tecnologias no manejo reprodutivo. Revista Terceira Margem Amazônia. 2(9): 140-159, 2017.

Pinheiro, R.R.; Gouveia, A.M.G; Alves F.S.F.; Haddad, J.P.A. Aspectos epidemiológicos da caprinocultura cearense. Arquivo Brasileiro de Medicina Veterinária e Zootecnia, 52(5): 534-543, 2000.

Pugh, D.G. Enfermidades do Sistema Músculo Esquelético. In: Clínica de caprinos e ovinos. São Paulo: Roca, 2004. p.252-256.

Quinn, P.J.; Markey; B.K.; Carter; M.E.; Donnelly, W.J.; Leonard, F.C. Microbiologia veterinária e doenças infecciosas. Porto Alegre: Artmed, 2005. p. 512.

Ribeiro, L.A.O. Foot rot dos ovinos. In: RietCorrea, F.; Schild, A.L.; Lemos, R.A.A.; Borges, J.R.J. Doenças de ruminantes e equinos. v.1. $3^{\text {a }}$ ed. São Paulo: Varela, 2007. p. 295-305.

Riet-Correa, F. Mortalidade perinatal em ruminantes. In: Riet-Correa, F.; Schild, A.L.; Lemos, R.A.A.; Borges, J.R.J. Doenças de ruminantes e equinos. v.2. $3^{\mathrm{a}}$ ed. São Paulo: Varela; 2007. p. 455-467.

Riet-Correa, B.; Simões, S.V.D.; Pereira, J.M.F.; Azevedo, S.S.; Melo, D.B.; Batista, J.A.; Miranda, E.G.N..; Riet-Correa, F. Sistemas produtivos de caprinocultura leiteira no semiárido paraibano: caracterização, principais limitantes e avaliação de estratégias de intervenção. Pesquisa Veterinária Brasileira, 33(3): 345-352, 2013.

Sandoval, P.; Oliveira, R.V; Bezerra, F.H; Mendes, C.Q.; Figueredo, R.R. Manual de criação de caprinos e ovinos. $1^{\text {a }}$ ed. Brasília: IABS, 2015. 144p.

Santos, T.C.P.; Alfaro, C.E.P.; Figueiredo, S.M. Aspectos sanitários e de manejo em criações de caprinos e ovinos na microrregião de Patos, Região semiárida da Paraíba. Ciência Animal Brasileira, 12(2): 206-0212, 2011.

Silva, R.A.B.; Batista, M.C.S.; Nascimento, C.B.; Alves, R.P.A.; Alves F.S.F.; Pinheiro, R.R.; 
Sousa, M.S.; Diniz, B.L.M.; Cardoso, J.F.S.; Paula, N.R.O. Caracterização zoosanitária da ovinocultura e caprinocultura na microrregião homogênea de Teresina, Piauí, Brasil. Arquivos do Instituto Biológico, 78(4): 593-598, 2011.

Silva, A.P.S.P.; Santos, D.V.; Kohek, I.; Machado, G.; Hein, H.E.; Vidor, A.C.M.; Corbellini, L. G. Ovinocultura do Rio Grande do Sul: descrição do sistema produtivo e dos principais aspectos sanitários e reprodutivos. Pesquisa Veterinária Brasileira, 33(12): 1453-1458, 2013a.

Silva, E.M.N.; Souza, B.B.; Silva, G.A.; Azevedo, S.S.; Gomes, T.L.S. Caracterização dos sistemas produtivos de leite de cabra nos cariris paraibano. Revista Caatinga, 26(1): 63-71, $2013 \mathrm{~b}$.

Sório, A.; Oliveira, A.; Ribeiro, E.A.A.; Costa, M.M.; Silva, M.C.F.; Oliveira, S.R.; Aguiar, V.M. Secretaria do Desenvolvimento da Agricultura e Pecuária. Diagnóstico da oferta e demanda de ovinos e caprinos para processamento de carne, pele e leite na região Central do Tocantins, 2017. Disponível em: <https://central3.to.gov.br/arquivo/405313>. Acesso em: 20 nov. 2019.

Tadich, N.; Hernandez, M. Prevalencia de lesiones podales en ovinos de 25 exploraciones familiares de la provincia de Valdivia, Chile. Archivos de Medicina Veterinária, 32(1): 63-74, 2000. 